\title{
Dust exposure and pneumoconiosis in a South African pottery. 2 Pneumoconiosis and factors influencing reading of radiological opacities
}

\author{
D Rees, $M$ Steinberg, P J Becker, A Solomon
}

\begin{abstract}
A cross sectional radiological survey of workers exposed to pottery dust during the manufacture of wall tiles and bathroom fittings was conducted in a South African factory. Roughly one third of workers with 15 or more years of service in high dust sections of the factory had pneumoconiosis. Previously undiagnosed advanced cases, including two with progressive massive fibrosis, were working in dusty occupations. A firm diagnosis of potters' pneumoconioisis was made in 11 of the 358 workers radiographed; all had served more than 10 years suggesting that radiography of workers with more than 10 years service would be a successful case finding strategy in South Africa. A combination of rounded and irregular opacities was the most common radiological finding in the workers with pneumoconiosis $(55 \%)$. Three readers reported on the chest radiographs, and all found an association between small radiological opacities, which were usually irregular or a combination of irregular and rounded, and exposure to pottery dust. The occurrence of irregular radiological opacities in workers exposed to pottery dust deserves further study. The least experienced reader significantly associated age with small opacities when duration of service (years) was used to measure exposure to dust. Sex was not an important predictor of radiological changes consistent with pneumoconiosis. Breast shadows were not an important cause of false positive readings and participating women did not develop pneumoconiosis after less exposure than men.
\end{abstract}

National Centre for Occupational Health, PO Box 4788, Johannesburg 2000, South Africa

D Rees, $M$ Steinberg

Institute for Biostatistics, PO Box 17555, Hilbrow 2038, South Africa

P J Becker

University of Witwatersrand

A Solomon
A cross sectionai study to identify workers with pneumoconiosis was conducted in a South African pottery manufacturing wall tiles and sanitary ware. A detailed investigation of concentrations of dust in workplace air was undertaken at the same time (results of this investigation and the work process at the factory are reported in a companion article ${ }^{1}$ ). The data gathered during the study were used:

(1) to calculate the prevalence rates of pneumoconiosis,

(2) to describe the radiological features of a series of cases with potters' pneumoconiosis. This objective was included as there are few recent publications on this subject. ${ }^{23}$ The 1980 version of the International Labour Office (ILO) international classification of radiographs of pneumoconioses ${ }^{4}$ has thus been applied infrequently to describe potters' pneumoconiosis and the radiological features of the condition are not as well described, in present day terminology, as might be expected. This would be unimportant if these workers were exposed to quartz only; the radiological picture of silicosis is well known, but, as they are exposed to kaolin and quartz, ${ }^{1}$ silicosis, mixed dust fibrosis, ${ }^{5}$ and kaolinosis, ${ }^{6-8}$ or a combination, are possible in theory. The effects of these conditions are less well established.

(3) to describe the histological findings in a case of potters' pneumoconiosis. This objective was possible as one of the workers with pneumoconiosis died shortly after the study and a post mortem examination was performed.

(4) to investigate the relation between opacities on the chest radiographs and age, smoking, sex, and exposure to pottery dust so that factors influencing the $x$ ray film readers to report opacities could be identified. This analysis was undertaken so that the significance of small opacities, particularly irregular opacities, in the diagnosis of pneumoconiosis in pottery workers could be evaluated.

Subjects and methods

THE WORKPLACE AND SURVEY PROCEDURE

The factory, which employed 509 workers, made wall tiles and small bathroom fittings. The raw materials, work processes, and respirable dust concentrations in air in the workplace are described elsewhere. $^{1}$ 
The survey was conducted at the workplace over a convenient two week period. After obtaining written consent, a questionnaire covering personal details and occupational history was administered by the principal researcher or a trained nursing sister based at the workplace. A full sized, $80 \mathrm{kV}$, posteroanterior chest radiograph was taken for each participating worker using a mobile $x$ ray machine.

To increase the response rate of workers with relatively long duration of service, all workers with more than four years of service were identified using personnel department records, and were encouraged to participate. This resulted in $87 \%$ (256) of the 294 workers with service exceeding four years presenting for study. Forty seven per cent of workers with shorter service (102) responded bringing total participation to $358(70 \%)$. One hundred and ninety five $(54.5 \%)$ of the participants were men and 163 $(45.5 \%)$ were women.

\section{METHODS}

Three independent readers experienced in the ILO international classification of radiographs of pneumoconioses ${ }^{4}$ analysed each film blind to clinical and exposure details. Pneumoconiosis was diagnesed if two of the three readers agreed that there were small radiological opacities of profusion $1 / 0$ or more, or if large opacities were present. The subjects in whom at least two of the three readers reported opacities of profusion $1 / 0$ or more had a physical examination, lung function tests, and appropriate laboratory investigations so that cases with diseases other than pneumoconiosis (for instance, cardiac failure) could be excluded from analysis. No case was excluded as a result of this evaluation.

\section{EXPOSURE TO FIBROGENIC DUST}

Two variables were used to quantify exposure to fibrogenic dust for each worker. These were duration of service (years) in a wall tile or sanitary ware factory and an exposure index based on respirable quartz concentration in workplace air. Exposure to respirable quartz was assessed by dividing the factory into three exposure areas, namely high dust, high dust/ low quartz, and low dust, based on respirable dust concentrations and quartz content of this dust. ${ }^{1}$ The median respirable dust concentrations for the three exposure areas were 1.3 (27\% quartz), 1.9 (7\% quartz), and $0.2 \mathrm{mg} / \mathrm{m}^{3}$ respectively. To account for the relatively low quartz content of dust in the high dust/low quartz area (about $25 \%$ of that in the high dust area) exposure intensity was considered as $\mathbf{0 . 2 5}$ times the measured median dust concentration $(0.25 \times 1.9)$. To derive the exposure index, exposure was standardised to the low dust area.

Maintenance and electrical workers spent roughly $50 \%$ of their time in high dust and $50 \%$ in non-dusty areas. Only a small proportion of their time involved dusty maintenance work, this group was thus exposed on average to dust concentrations half as high as the high exposure group and were placed in an intermittent high dust category with exposure intensity $50 \%$ of the high dust area $(0.5 \times 1.3)$.

Cumulative exposure index for quartz (quartz index) was calculated for individual workers by summing the products of the exposure index and years of service for each section of the workplace in which a worker had ever worked.

The quartz index was based on median dust concentrations, a slightly more conservative measure of average respirable dust concentrations than the mean. ${ }^{1}$ This did not materially affect the index as the mean and median concentrations were sufficiently similar to make the index about the same when calculated from either. For example, the quartz index (mean) and quartz index (median) for 10 years in a high exposure area was 85 and 65 respectively, both substantially larger than the quartz index of 10 for 10 years in a low exposure area.

Respirable dust concentrations were not measured in every section of the factory; forty nine workers who had service in unmeasured sections were excluded from the calculation of the quartz index. Forty three with two or more years service in any dusty workplace other than the study workplace were also excluded.

\section{DATA ANALYSIS}

Stepwise logistic regression was used to investigate the relations between the outcome variable small opacities $1 / 0$ or more, and the independent variables, duration of service, quartz index, age, sex, and smoking (current or never only; ex-smokers $(\mathbf{n}=36)$ were excluded). Small opacities were considered as a dichotomous variable, with profusion $1 / 0$ or greater representing a positive outcome.

Stepwise multiple linear regression analysis was used to examine the relation between profusion of opacities and the variables, quartz index, sex, age, and smoking. Profusion of opacities was scored on a scale of 1 to $12(0 /-$ to $3 /+)$ and was based on the median profusion of the three readers. For example, $1 / 1,1 / 0$ and $1 / 1$ would have a median of $1 / 1$ and be scored 5 on the 12 point scale.

Data were analysed with the help of BMDP statistical software. ${ }^{9}$

\section{Results}

PREVALENCE OF PNEUMOCONIOSIS

Table 1 presents radiological changes consistent with pneumoconiosis for individual readers by shape of small opacity and progressive massive fibrosis. Reader 3 found a crude prevalence of changes consistent with simple pneumoconiosis of 109/1000, much higher than the other two (36 and 34/1000). Progressive massive fibrosis was diagnosed in two 
Table 1 Opacities consistent with pneumoconiosis by reader and shape of opacity

\begin{tabular}{|c|c|c|c|c|c|c|}
\hline & \multicolumn{2}{|l|}{ Reader 1} & \multicolumn{2}{|l|}{ Reader 2} & \multicolumn{2}{|l|}{ Reader 3} \\
\hline & No $(\%)^{\star}$ & Prevalence (per 1000) & No $(\%)^{\star}$ & Prevalence (per 1000) & No $(\%)^{\star}$ & Prevalence (per 1000) \\
\hline \multicolumn{7}{|c|}{ Simple } \\
\hline $\begin{array}{l}\text { Irregular only } \\
\text { Mixed } \dagger \\
\text { Rounded only }\end{array}$ & $\begin{array}{l}2(15) \\
8(62) \\
3(23)\end{array}$ & $\begin{array}{r}6 \\
22 \\
8\end{array}$ & $\begin{array}{l}6(50) \\
2(17) \\
4(33)\end{array}$ & $\begin{array}{r}17 \\
6 \\
11\end{array}$ & $\begin{array}{r}20(51) \\
12(31) \\
7(18)\end{array}$ & $\begin{array}{l}56 \\
34 \\
20\end{array}$ \\
\hline Total & $13(100)$ & 36 & $12(100)$ & 34 & $39(100)$ & 109 \\
\hline \multicolumn{7}{|c|}{ Progressive massive fibrosis } \\
\hline & 1 & 3 & 2 & 6 & 2 & 6 \\
\hline
\end{tabular}

$\star \%$ of cases with opacities consistent with pneumoconiosis.

†A combination of rounded and irregular opacities; predominant opacity either rounded or irregular.

cases-by all three readers in one worker and by two readers in the other.

Applying the stricter diagnostic criteria for pneumoconiosis described in the methods section (agreement between two readers and clinical evaluation) a diagnosis of pneumoconiosis was made in 14 cases. Data for these 14 cases are listed in table 2 for each reader by profusion and shape/size, of small opacities. Case 6 was the only woman. Although all 14 cases had features consistent with pneumoconiosis only 11 could be attributed to exposure in the study workplace. Case 1 had 21 years of exposure to dust but only two were in the pottery industry. Case 2 probably did not have potters' pneumoconiosis as he had received a social pension for respiratory disease before starting at the pottery, and case 3 had only 5.5 years of exposure and the three readers reported small opacities of profusion $0 / 0,1 / 0$, and $1 / 0$; making this a borderline case of pneumoconiosis. Exclusion of these three cases resulted in a crude prevalence for pneumoconiosis of $31 / 1000$. This increased to $43 /$
1000 for workers with more than four years of service and to $316 / 1000$ for workers who had worked in a section classified as high dust for 15 years or longer.

NATURE OF OPACITIES IN POTTERS' PNEUMOCONIOSIS Tables 1 and 2 show the nature of the radiological opacities. Irregular opacities were reported as the only opacity in a fairly large percentage of abnormal chest radiographs by all three readers $(15 \%, 50 \%$, and $51 \%$; table 1 ), suggesting that irregular opacities may be a feature of potters' pneumoconiosis. As pneumoconiosis was accepted only when at least two readers reported opacities, however, irregular opacities were less prominent (table 2). Cases 1-3 probably did not have potters' pneumoconiosis. Of the remaining 11 only one case (11) had irregular opacities alone (these were associated with progressive massive fibrosis) but six ( $55 \%$ ) had both rounded and irregular opacities. Rounded opacities were more frequently reported in the cases with greater profusion of opacities.

Table 2 The 14 workers in whom at least two readers read pneumoconiosis by duration of service and profusion (Prof), shape-size $(S-S)$, and lung zone for each reader

\begin{tabular}{|c|c|c|c|c|c|c|c|c|}
\hline \multirow[b]{2}{*}{ Case } & \multirow{2}{*}{$\begin{array}{l}\text { Duration of } \\
\text { service }(y)\end{array}$} & \multicolumn{2}{|c|}{ Reader 1} & \multicolumn{2}{|c|}{ Reader 2} & \multicolumn{2}{|c|}{ Reader 3} & \multirow{2}{*}{$\begin{array}{l}\text { All three readers } \\
\text { Predominant shape }\end{array}$} \\
\hline & & Prof & $S-S$ & Prof & $S-S$ & Prof & $S-S$ & \\
\hline
\end{tabular}

«Numbers in parentheses are years of service in non-survey dusty workplaces.

+ Progressive massive fibrosis; worker 11 ' $A$ ' lesion, worker 14 ' $C$ ' lesion.

$\ddagger$ Egg shell calcification of hilar glands. 
Table 3 Workers considered for logistic regression analysis on duration of service and quartz index

\begin{tabular}{lcc}
\hline & $\begin{array}{c}\text { Duration } \\
\text { of service }\end{array}$ & $\begin{array}{l}\text { Quartz } \\
\text { index }\end{array}$ \\
\hline No of survey participants (\%) & $291(81 \cdot 3)$ & $234(65 \cdot 4)$ \\
Opacities: & $9(3 \cdot 1)$ & $8(3 \cdot 4)$ \\
$\quad$ Reader 1 (\%)* & $10(3 \cdot 4)$ & $9(4 \cdot 3)$ \\
$\quad$ Reader 2(\%) & $29(10)$ & $26(11)$ \\
$\quad$ Reader 3(\%) & & \\
Duration of service (y): & $9 \cdot 2$ & $8 \cdot 2$ \\
Mean & $1-36$ & $1-36$ \\
Range & 45 & 28 \\
Men $>10$ & 45 & 33 \\
Women >10 & & \\
Smoking state: & $132(45)$ & $104(44)$ \\
Current (\%) & $159(55)$ & $130(56)$ \\
Never (\%) & & \\
Age: & $38 \cdot 2$ & $37 \cdot 4$ \\
Mean & $20-68$ & $20-68$ \\
Range &
\end{tabular}

*Percentage of participants with opacities on chest radiograph.

\section{HISTOLOGICAL FEATURES}

One of the workers with pneumoconiosis (case 13) died five months after the survey. A postmortem examination was performed and three pathologists experienced in occupational lung disease reported on the histology.

He had had only one job: 31 years in tilemaking at the study pottery. Table 2 presents the radiological features. The first pathologist found islets of silicotic collagenisation and massive fibrosis in the lungs. The second pathologist reviewed the histology and found the same abnormalities but also reported stellate lesions typical of mixed dust fibrosis. The third confirmed the presence of mixed dust fibrosis. None found evidence of tuberculosis.

\section{FACTORS INFLUENCING THE READING OF OPACITIES}

The difference in frequency of opacities reported by the three readers (table 1 ) as well as the large proportion of abnormal radiographs with irregular opacities found by readers 2 and 3 in particular, prompted an analysis of the factors influencing the reading of these radiological changes. Stepwise logistic regression was used to analyse the data. Workers satisfying entry criteria for the stepwise logistic regression, as described in the methods sections on exposure to fibrogenic dust and data analysis, are presented in table 3 . Reader 3 found many more workers with small opacities than did either reader 1 or $2(29,9$, and 10 respectively for duration of service). Not shown in table 3 is that most of these opacities reported by reader 3 were irregular only $(51 \%)$ or a combination of irregular and rounded (31\%). Reader 1 found $67 \%$ to be a combination of irregular and rounded and $22 \%$ to be rounded opacities only, whereas reader 2 observed $60 \%$ to have irregular and $30 \%$ to have rounded opacities. Men and women with long service, as well as current and non-smokers, were well represented in the duration of service and quartz index groups.

Table 4 gives the results of the logistic regression. The associations between the explanatory variables, exposure (as duration of service or quartz index), smoking, age, and sex, and the outcome variable (small opacities $1 / 0$ or greater) are presented. Readers 1 and 2 were similar in that the variable which explained most of the variance in the outcome

Table 4 The association between small opacities and exposure, smoking, age, and sex for each reader

\begin{tabular}{|c|c|c|c|c|c|c|c|c|}
\hline \multirow[b]{2}{*}{ Type of index } & \multicolumn{2}{|c|}{ Exposure } & \multicolumn{2}{|c|}{ Smoking } & \multicolumn{2}{|l|}{ Age } & \multicolumn{2}{|l|}{ Sex } \\
\hline & $\chi$ & $p$ Value & $\chi$ & p Value & $\chi$ & p Value & $\chi$ & p Value \\
\hline \multicolumn{9}{|l|}{ Reader 1: } \\
\hline $\begin{array}{l}\text { Duration }(y) \S \\
\text { Quartz index }\end{array}$ & $\begin{array}{l}17 \cdot 2^{\star} \\
27 \cdot 3^{\star}\end{array}$ & $\begin{array}{l}0.001 \\
0.001\end{array}$ & $\frac{4 \cdot 1 \dagger}{-}$ & $\begin{array}{l}0.042 \\
\text { NS }\end{array}$ & - & $\begin{array}{l}\text { NS } \\
\text { NS }\end{array}$ & 二 & $\begin{array}{l}\text { NS } \\
\text { NS }\end{array}$ \\
\hline \multicolumn{9}{|l|}{ Reader 2: } \\
\hline $\begin{array}{l}\text { Duration } \\
\text { Quartz index }\end{array}$ & $\begin{array}{l}17 \cdot 4^{\star} \\
27 \cdot 6^{\star}\end{array}$ & $\begin{array}{l}0.001 \\
0.001\end{array}$ & ${ }^{5 \cdot 4 \dagger}$ & $\begin{array}{l}0.02 \\
\text { NS }\end{array}$ & $-^{3.0 \ddagger}$ & $\begin{array}{l}0.084 \\
\text { NS }\end{array}$ & $\overline{9 \cdot 2 \dagger}$ & $\begin{array}{l}\text { NS } \\
0.002\end{array}$ \\
\hline $\begin{array}{l}\text { Reader 3: } \\
\text { Duration } \\
\text { Quartz index }\end{array}$ & $\begin{array}{l}2 \cdot 7 \ddagger \\
9 \cdot 0 \dagger\end{array}$ & $\begin{array}{l}0.098 \\
0.002\end{array}$ & $\begin{array}{l}6 \cdot 8 \dagger \\
3 \cdot 1 \ddagger\end{array}$ & $\begin{array}{l}0.009 \\
0.077\end{array}$ & $\begin{array}{l}27 \cdot 2^{\star} \\
21 \cdot 7^{\star}\end{array}$ & $\begin{array}{l}0.001 \\
0.001\end{array}$ & 二 & $\begin{array}{l}\text { NS } \\
\text { NS }\end{array}$ \\
\hline \multicolumn{9}{|c|}{ Three readers combined: } \\
\hline $\begin{array}{l}\text { Duration } \\
\text { Quartz index }\end{array}$ & $\begin{array}{l}14 \cdot 8^{\star} \\
28 \cdot 9^{\star}\end{array}$ & $\begin{array}{l}0.001 \\
0.001\end{array}$ & $=$ & $\begin{array}{l}\text { NS } \\
\text { NS }\end{array}$ & $\mathbf{3}^{3 \cdot 7 \ddagger}$ & $\begin{array}{l}0.054 \\
\text { NS }\end{array}$ & $\begin{array}{l}6 \cdot 6 \ddagger \\
4 \cdot 2 \dagger\end{array}$ & $\begin{array}{l}0.01 \\
0.04\end{array}$ \\
\hline
\end{tabular}

*Variable entered into regression first.

+Variable entered into regression second.

†Variable entered into regression third.

Duration $=$ duration of service.

NS $\mathrm{p}>0 \cdot 1$. 
Table 5 Association between small opacities and exposure, age, and sex in non-smokers for reader 3

\begin{tabular}{|c|c|c|c|c|c|c|}
\hline \multirow[b]{2}{*}{ Type of index } & \multicolumn{2}{|c|}{ Exposure } & \multicolumn{2}{|l|}{ Age } & \multicolumn{2}{|c|}{ Sex } \\
\hline & $\chi$ & p Value & $\chi$ & p Value & $\chi$ & p Value \\
\hline $\begin{array}{l}\text { Duration of service }(y) \\
\text { Quartz index }\end{array}$ & $\overline{5 \cdot 3 \star}$ & $\begin{array}{l}\text { NS } \\
0.021\end{array}$ & $5^{5 \cdot 1^{\star}}$ & $\begin{array}{l}0.020 \\
\text { NS }\end{array}$ & - & $\begin{array}{l}\text { NS } \\
\text { NS }\end{array}$ \\
\hline
\end{tabular}

^Entered into regression first.

NS $p>0 \cdot 1$.

variable was exposure. When exposure was measured as duration of service, smoking was a significant independent predictor of small opacities by both these readers $(p<0.05)$. Age and sex were associated with small opacities by reader 3 and reader 2 respectively.

Combining the three readers by considering opacities present only when two or more readers agreed resulted in a significant association between sex and small opacities. Because only one woman had opacities in the combined readers' series it can be concluded that being a man was independently associated with a positive $x$ ray film reading.

One explanation for the difference between reader 3 and the other readers is that reader 3 read the radiological effects of aging into the ILO classification. To examine this hypothesis more closely the possible confounding effects of smoking were removed by repeating the logistic regression for non-smokers only. The non-smokers were predominantly women $(80 \%)$ but the mean ages of smokers and nonsmokers were similar (within one year). Readers 1 and 2 reported a positive outcome for small opacities in only two non-smokers; further analysis of these two readers was, therefore, not performed. Reader 3 found 10 non-smokers with small opacities; these were irregular in five, mixed in four, and rounded in 1 .

Table 5 shows the results of the logistic regression analysis. Despite the fact that rounded opacities occurred in only one worker, the cumulative exposure index for quartz was a significant independent predictor of a positive outcome in non-smokers. Age was associated with small opacities when duration of service, the most time dependent measure of exposure, was an explanatory variable in the regression equation.

The stepwise multiple linear regression analysis showed a relation between profusion of opacities and the independent variables quartz index and sex only. This relation is described by the regression line: profusion of opacities $=1.83+0.14 \times$ quartz index $-0.3 \times$ sex, where sex was a dummy variable with 0 being men and 1 women. The coefficient of determination $\left(\mathrm{R}^{2} \times 100 \%\right)$ was $32.5 \%$ and quartz index entered the stepwise analysis first.

\section{Discussion}

The first objective of this study was to examine prevalence of pneumoconiosis. Applying relatively stringent diagnostic criteria (at least two readers diagnosing pneumoconiosis and exclusion of three cases unlikely to be potters' pneumoconiosis) resulted in a prevalence of $43 / 1000$ for workers with more than four years of service. The good response rate of workers in this category of service $(87 \%)$ increases the probability that this is an accurate measure of prevalence of pneumoconiosis in this factory. Of greater interest is the finding that about one third of long service (15 or more years) workers exposed to high dust had pneumoconiosis. This high proportion did not result in a large number of cases of pneumoconiosis as only a small number of workers had long service. It is anticipated, however, that an increasing proportion of South Africans will work for long periods in one job. Consequently an increase in the number of workers with occupational lung disease will occur unless dust control is improved.

All 11 workers with a firm diagnosis of potters' pneumoconiosis (cases 4-14, table 2) had more than 10 years of exposure to pottery dust. This suggests that if workers with 10 or more years of service in dusty sections of South African potteries were radiographed, a large proportion of currently employed workers with pneumoconiosis would be identified. Radiography of these workers with long service should thus form the first step in a strategy to identify South African pottery workers with pneumoconiosis. Studies elsewhere support the view that few cases would be missed if this plan were implemented. For example, Swaen $e t$ al ${ }^{10}$ found 33 cases of silicosis in 1975 workers at two large Dutch earthenware factories; all of them had more than 10 years of service. The need to consider simple case finding strategies is shown by the identification of people with previously undiagnosed advanced pneumoconiosis, including progressive massive fibrosis, working in dusty areas of the study factory. The presence of advanced undetected cases can be explained by the absence of systematic monitoring of workers for occupational lung disease. This is not unusual as there are no statutory obligations for the medical examination of South African workers in 
non-mining industries. Regulations to rectify this situation are required urgently.

Only 11 workers were accepted as definite cases of potters' pneumoconiosis thus limiting the number of people in whom the radiological features of this condition could be examined. Nevertheless, it is of interest that six of these 11 workers had a combination of irregular and rounded opacities, and that only four $(36 \%)$ had purely rounded opacities. Small opacities typical of the shape most commonly seen in simple silicosis (rounded opacities $1-3 \mathrm{~mm}$ in size ${ }^{11}$ ) were, therefore, reported less frequently than expected. One possible explanation for this finding is that exposure to respirable dust containing more than one fibrogenic material (quartz and kaolin) produced radiological features different from those most commonly seen in pneumoconiotic subjects exposed only to quartz.

It should be noted though that this series was identified during a cross sectional survey that omitted an unknown number of workers with pneumoconiosis who had left the factory before the survey. It is possible, therefore, that chance or an unidentified selection bias resulted in an unusual collection of pneumoconiotic subjects. Also, table 2 shows that advanced cases $(5,7,10,12,13$, and 14$)$ generally had rounded opacities; suggesting that difficulties in reading early changes into the ILO classification may partly explain the atypical radiological findings.

The histologically confirmed case of mixed dust fibrosis was exposed to dust with a quartz content above $25 \% .^{1}$ Relatively high concentrations of quartz do not prevent mixed dust fibrosis, as has been suggested by McLaughlin ${ }^{12}$ and Elmes ${ }^{13}$ and this result supports the findings of Goldstein and Rendall. ${ }^{14}$

Stepwise logistic regression was used to identify factors that may have resulted in the $x$ ray film readers finding small opacities on the chest radiographs. These opacities should not be considered synonymous with pulmonary fibrosis in interpreting the results of this analysis as not all workers with $x$ ray films consistent with pneumoconiosis as scored by ILO will have histological evidence of the disease. ${ }^{15}$ Nevertheless, when the opacities are strongly associated with exposure to dust a dust related effect on the lungs or smaller airways is implied. The analysis of factors influencing the reading of small opacities had at least two limitations. Smoking was considered as an all or nothing variable (current or never) rather than an estimate of dose such as packyears. Grouping light short duration smokers with heavy long term smokers prevented closer examination of the association between smoking, age, and small opacities. For example, a relation between increasing age and longer duration of smoking might explain why all three readers found that current smoking and small opacities were significantly associated when duration of service (usually an age linked variable) was used as a surrogate for exposure to dust, but not when quartz concentrations (quartz index) were used. The second limitation was that the small number of positive outcomes for reader 1 and 2 meant that irregular and rounded opacities could not be considered separately, thus reducing investigation of the association between exposure to pottery dust and type of opacity. Despite these two limitations, some interesting observations on the significance of small radiological opacities in these pottery workers could be made. For both readers 1 and 2 quartz index explained the variance in small opacities very well and it is reasonable to assume that these two readers were reading the radiological effects of exposure to pottery dust. It is of interest, therefore, that both readers 1 and 2 saw rounded opacities as the only opacity in a small proportion of workers with opacities $(22 \%$ and $30 \%$ respectively). The ILO system of classifying radiographs is not ideal and the findings of one group of readers, may not be generalisable to others. The presence of irregular opacities as a result of exposure to pottery dust, nevertheless, is suggested by this finding, and deserves further investigation, particularly since a possible effect of siliceous dust in the production of irregular opacities has been suggested in other studies. For example, an association was found between exposure to dust in South African gold mines and the reading of iregular opacities. ${ }^{15}$

Reader 3 was the least experienced and examination of the logistic regression analysis suggests that radiological signs of increased age, or a factor relatec to age but not identified as a dust related variable were read into the ILO classification by this reader Despite this age factor table 5 shows that an association between pottery dust, as measured by quart: index and irregular opacities either alone or ir combination with rounded opacities, was found br reader 3. Exposure to dust alone may not be the causi of this association as complex interrelations betweer smoking, dust exposure, and to a lesser extent age have been reported ${ }^{16}{ }^{17}$ and may explain the findings it this study.

Two observations, in addition to the association between irregular opacities and pottery dust, can $b$ made. The first is that epidemiological investigation that consider the effect of variables such as smokin and age on the production of radiological opacities i: workers may require information on the intensity $c$ exposure as well as the duration. The apparen relation between smoking and small opacities in thi study, found only when duration of service was use as a measure of exposure, illustrates this point. $\mathrm{Th}$ second concerns sex and pneumoconiosis. Gerhards son and Ahlmark ${ }^{18}$ found that women with silicos: entered into the Swedish Pneumoconiosis Regist had a shorter duration of service in dusty workplact 
than men with silicosis. One explanation offered by the authors is that women are at an increased risk, at the same level of exposure, of developing silicosis. Our study provided data to test their hypothesis as women had long service in dusty occupations (for example, fettling) in bathroom fitting and tile manufacture, both high dust sections of the factory. ${ }^{1}$ Little support for an increased risk in women could be found as only one woman had a firm diagnosis of pneumoconiosis and the regression analyses (logistic and stepwise linear) showed an association between being male and small opacities. Also it can be concluded that breast shadows did not cause readers to report opacities.

In summary, an association between small opacities, which were usually irregular or a combination of irregular and rounded, and exposure to pottery dust was found by all three readers. Age was significantly associated with a positive reading by the least experienced reader provided smokers and nonsmokers were grouped together or duration of service was used to measure exposure to dust. Smoking was only important if duration of service provided the measure of exposure. Sex was not an important predictor of radiological changes consistent with pneumoconiosis.

In conclusion, this study showed that pneumoconiosis remains an important occupational health issue for the South African pottery industry as a high proportion of long service workers with high exposure had the disease and because workers with undetected advanced pneumoconiosis were working in dusty occupations. The occurrence of irregular radiological opacities in workers exposed to pottery dust deserves further attention.

We thank the workers and management of the pottery for their cooperation. We would also like to thank the $x$ ray film readers, Professor A Solomon and Drs Louw and Erhlich, as well as $\mathrm{K}$ Botha for assistance with management of data. $\mathrm{Dr}$ Sluis-Cremer, Professor Davies, and Dr Felix provided valuable comments on earlier versions of the paper.

1 Rees D, Cronje R, du Toit RSJ. Dust exposure and pneumoconioisis in a South African Pottery. 1 Study objectives and dust exposure. Br J Ind Med 1992;49:459-64.

2 Prowse K, Allen MB, Bradbury SP. Respiratory symptoms and pulmonary impairment in male and female subjects with pottery workers' pneumoconiosis. Ann Occup Hyg 1989;33:375-85.

3 Rees D. A radiological survey of a ceramic factory manufacturing wall tiles and small bathroom fittings. Johannesburg: University of Witwatersrand Medical School, 1989. (MSc(med) thesis.)

4 International Labour Office. Guidelines for the use of the ILO international classification of radiographs of pneumoconioses, rev ed. Geneva: International Labour Office, 1980.

5 Posner E. Pneumoconiosis in the north Staffordshire pottery industry. In: Davies CN, ed. Health conditions in the ceramic industry. London: Pergamon Press, 1969:18.

6 Morgan W, Donner A, Higgins I, Pearson M, Rawlings W, Bracken M. The effects of kaolin on the lung. Am Rev Respir Dis 1988;138:813-20.

7 Altekruse E, Chaudhary B, Pearson M, Morgan W. Kaolin dust concentrations and pneumoconiosis at a kaolin mine. Thorax 1984;39:436-41.

8 Wagner J, Pooley F, Gibbs A, Lyons J, Sheers G, Moncrieff C. Inhalation of china stone and china clay dusts: relationship between the mineralogy of dust retained in the lungs and pathological changes. Thorax 1986;41:190-6.

9 Dixon WJ. BMDP statistical software. Los Angeles: University of California Press, 1985.

10 Swaen GMH, Passier PECA, Van Attekum AMNG. Prevalence of silicosis in the Dutch fine-ceramic industry. Int Arch Environ Health 1988;60:71-4.

11 Parkes WR. Occupational lung disorders. London: Butterworths 1982:147.

12 McLauglin AIG. Pneumoconiosis in foundry workers. British Journal of Tuberculosis 1957;51:297-309.

13 Elmes PC. Inorganic dust. In: Raffle PAB, Lee WR, McCallum RI, Murray R, eds. Hunters' diseases of occupations. London: Hodder and Stoughton, 1974.

14 Goldstein B, Rendall REG. The relative toxicities of the main classes of minerals. In: Shapiro HA, ed. Pneumoconiosis: proceedings of the international conference 1969. Cape Town: Oxford University Press, 1970:429-434.

15 Sluis-Cremer GK, Hessel PA, Hnizdo E. Factors influencing the reading of small opacities in a radiological survey of asbestos miners in South Africa. Arch Environ Health 1989;44:237-43.

16 Kilburn KH, Lilis R, Anderson H, Miller A, Warshaw R. Interaction of asbestos, age and cigarette smoking in producing radiographic evidence of diffuse pulmonary fibrosis. $\mathrm{Am} \mathrm{J}$ Med 1986;80:377-81.

17 Blanc PD. Cigarette smoking and pneumoconiosis: structuring the debate. Am J Ind Med 1989;16:1-4.

18 Gerhardsson L, Ahlmark A. Silicosis in women. Experience from the Swedish Pneumoconiosis Register. J Occup Med 1985;27:347-50.

Accepted 4 November 1991 